\title{
Investigations of the Taxonomy and Systematics of Fusobacterium nucleatum Using Allozyme Electrophoresis
}

\author{
MICHELLE L. MORRIS, ${ }^{1}$ R. H. ANDREWS, ${ }^{2}$ AND A. H. ROGERS ${ }^{1 *}$ \\ Microbiology Laboratory, Department of Dentistry, ${ }^{1}$ and Department of Microbiology and Immunology, ${ }^{2}$ \\ The University of Adelaide, Adelaide, South Australia, Australia
}

\begin{abstract}
Fusobacterium nucleatum forms part of the resident microbiota in both oral and extraoral sites in humans and animals. It is also involved in infections in such sites. Despite the genetic heterogeneity within the species, it has been divided into five subspecies, the validities of which have been questioned. In the present study, 44 $F$. nucleatum isolates were examined at 21 enzyme loci by using the allozyme electrophoretic technique to establish an accurate genetic framework for taxonomic purposes. Three distinct genetic clusters were identified; one cluster consisted exclusively of extraoral isolates, another cluster consisted predominantly of human oral isolates, and the third cluster consisted of a single human oral isolate. Our results highlight the urgent need for extensive biochemical, immunological, and epidemiological studies to accurately define the systematics of the genus Fusobacterium based on the framework derived in this study by using 21 independent genetic characteristics.
\end{abstract}

Isolates of Fusobacterium nucleatum have been identified in the oral cavities of healthy individuals and a number of extraoral sites, including the gastrointestinal tract (11), where this species constitutes part of the resident microbiota. However, fusobacterial species have also been isolated from a range of oral and extraoral infections $(1,16)$. The frequent isolation of these organisms from clinical infections suggests a pathogenic role for the genus Fusobacterium, but the virulence determinants remain largely unknown (11). Due to the weak fermentation reactions of fusobacterial species $(10,15)$, carbohydrate utilization tests, which are commonly used for routine diagnosis, are of little use, and thus an alternative identification technique that is rapid, simple, and accurate is required.

DNA-DNA homology experiments have indicated that $F$. nucleatum is particularly homogeneous and that its members exhibit 97.3 to $98.4 \%$ sequence similarity under optimal hybridization conditions (13). However, heterogeneity within the species has been observed in cellular and colonial morphologies $(5,6,10)$, in whole-cell soluble protein profiles (4), in enzyme electrophoretic patterns (12), in adhesive properties (24), in pyrolysis mass spectrometry analysis data (14), in rRNA gene restriction patterns (12), and in DNA-DNA hybridization data (13). This heterogeneity aids in the identification of members of the species and the division of the strains into taxonomically relevant groups, such as subspecies, but such efforts have not resulted in a widely accepted taxonomy $(4,6,7)$. The observed heterogeneity may explain the ability of this species to adapt to a variety of environments, as observed in the diversity of clinical diseases with which it is associated.

Within the species $F$. nucleatum, a number of investigators have identified a range of distinct genetic clusters which have subsequently been designated subspecies, but their results often do not correlate with each other $(4,6,7)$. Pyrolysis mass spectrometry (14) has been used to identify two distinct clusters within $F$. nucleatum oral isolates. Dzink et al. (4), using DNA homology techniques and electrophoretic patterns of whole-cell lipoproteins, identified three distinct groups within

\footnotetext{
* Corresponding author. Mailing address: Microbiology Laboratory, Department of Dentistry, The University of Adelaide, North Terrace, Adelaide, South Australia, 5005 Australia. Phone: 618303 5104. Fax: 618303 3444. E-mail: arogers@dentistry.adelaide.edu.au.
}

this species which were subsequently named $F$. nucleatum subsp. polymorphum, $F$. nucleatum subsp. nucleatum, and $F$. nucleatum subsp. vincentii. However, not all of the isolates tested could be classified as members of one of these subspecies. Gharbia and Shah identified four centers of variation by using cellular and colonial morphologies and the electrophoretic mobilities of the enzymes glutamate dehydrogenase and 2-oxoglutarate reductase $(6,7)$. DNA-DNA hybridization results obtained under optimal conditions indicated that the isolates in these four centers of variation should be placed in the same species due to their high levels of homology (12), and results obtained under stringent conditions were in agreement with the electrophoretic results (13). Lawson et al. subsequently identified these clusters as $F$. nucleatum subsp. polymorphum, $F$. nucleatum subsp. nucleatum, F. nucleatum subsp. fusiforme, and $F$. nucleatum subsp. animalis and confirmed this subdivision by differentiating the type strains of the four subspecies by rRNA gene restriction analysis (12). Gharbia et al. suggested that in the human oral cavity, $F$. nucleatum subsp. nucleatum is associated with periodontally diseased sites, while $F$. nucleatum subsp. polymorphum and $F$. nucleatum subsp. fusiforme are associated with healthy subgingival sites $(6,9)$. Despite this apparent correlation, there seems to be no difference in the putative virulence determinants of these proposed subspecies (8).

In our preliminary taxonomic study of previously assigned $F$. nucleatum subspecies and their designated type strains, we identified massive genetic heterogeneity within the isolates assigned to this species (17). Indeed, the heterogeneity was equivalent to that seen in other bacterial species divisions (18, 22 ). Furthermore, there was no correlation between any of the observed clusters of isolates and any of the designated type strains. Type strains representing previously designated subspecies often occurred in the same genetic cluster or subspecies. The results of this study highlighted the need for a total revision of the previously designated (genetic) divisions and the methods used for characterization, identification, and taxonomy of $F$. nucleatum.

The aims of the present study were to use previously identified diagnostic loci (17) to estimate the genetic variation within the species $F$. nucleatum by using isolates representing the range of known genetic diversity and to determine whether 
TABLE 1 . Origins of the $F$. nucleatum isolates tested

\begin{tabular}{|c|c|c|c|c|}
\hline Isolate & Subspecies & Host & Site of isolation or infection & Geographical origin \\
\hline ATCC $25586^{\mathrm{T}}$ & F. nucleatum subsp. nucleatum & Human & Periodontal disease & United States \\
\hline Fev-1 & F. nucleatum subsp. nucleatum & Human & Periodontal disease & United States \\
\hline VPI 5040 & F. nucleatum subsp. nucleatum & Human & Perirectal & United States \\
\hline VPI 9240 & F. nucleatum subsp. nucleatum & Human & Abdominal & United States \\
\hline ATCC $10953^{\mathrm{T}}$ & F. nucleatum subsp. polymorphum & Human & Healthy gingiva & United States \\
\hline D206A4 & F. nucleatum subsp. polymorphum & Human & Periodontal disease & United States \\
\hline F1 & F. nucleatum subsp. polymorphum & Human & Healthy gingiva & Berlin, Germany \\
\hline F3 & F. nucleatum subsp. polymorphum & Human & Healthy gingiva & Berlin, Germany \\
\hline VPI 8818 & F. nucleatum subsp. polymorphum & Human & Appendix & United States \\
\hline NCTC $11326^{\mathrm{T}}$ & F. nucleatum subsp. fusiforme & Human & Healthy gingiva & United States \\
\hline ATCC $49256^{\mathrm{T}}$ & F. nucleatum subsp. vincentii & Human & Healthy gingiva & United States \\
\hline D213B3 & F. nucleatum subsp. vincentii & Human & Healthy gingiva & United States \\
\hline D218B17 & F. nucleatum subsp. vincentii & Human & Healthy gingiva & United States \\
\hline VPI 4487R & F. nucleatum subsp. vincentii & Human & Leg & United States \\
\hline VPI 4487S & F. nucleatum subsp. vincentii & Human & Leg & United States \\
\hline VPI 6086 & F. nucleatum subsp. vincentii & Human & Rectal & United States \\
\hline VPI 6616D & F. nucleatum subsp. vincentii & Human & Rectal & United States \\
\hline VPI 8754A & F. nucleatum subsp. vincentii & Human & Scrotal & United States \\
\hline NCTC $12276^{\mathrm{T}}$ & F. nucleatum subsp. animalis & Monkey & Healthy colon & United States \\
\hline M 7731 & $\mathrm{ND}^{a}$ & Human & Ear & United Kingdom \\
\hline M 4322 & ND & Human & Abdominal & United Kingdom \\
\hline M 3832 & ND & Human & Dog bite & United Kingdom \\
\hline M 2109 & ND & Human & Pleural & United Kingdom \\
\hline SG2 & ND & Human & Healthy gingiva & Adelaide, Australia \\
\hline SV2 & ND & Human & Healthy gingiva & Adelaide, Australia \\
\hline G34 & ND & Human & Preterm labor & Adelaide, Australia \\
\hline I34 & ND & Human & Preterm labor & Adelaide, Australia \\
\hline I37 & ND & Human & Preterm labor & Adelaide, Australia \\
\hline 10976 & ND & Human & Brain & United States \\
\hline 10625 & ND & Human & Blood & United States \\
\hline AIP486-87 & ND & Human & Gastric & Paris, France \\
\hline 10772 & ND & Human & Pleural & United States \\
\hline 10554 & ND & Human & Appendix & United States \\
\hline 10735 & ND & Human & Appendix & United States \\
\hline 10213 & ND & Human & Foot & United States \\
\hline 10446 & ND & Human & Hand & United States \\
\hline 3322 & ND & Cat & Periodontal disease & Sydney, Australia \\
\hline 3352 & ND & Cat & Periodontal disease & Sydney, Australia \\
\hline 3943 & ND & Cat & Healthy gingiva & Sydney, Australia \\
\hline 3949 & ND & Cat & Healthy gingiva & Sydney, Australia \\
\hline KE255 & ND & Human & Brain & Perth, Australia \\
\hline KE393 & ND & Human & Vaginal & Perth, Australia \\
\hline OMZ439 & ND & Human & Periodontal disease & Switzerland \\
\hline F6 & ND & Human & Healthy gingiva & Berlin, Germany \\
\hline
\end{tabular}

${ }^{a}$ ND, not determined.

there were any correlations between genetically determined clusters of isolates and other biological parameters, such as site of infection, in order to establish an accurate, taxonomically relevant genetic framework for the species $F$. nucleatum and its proposed subspecies. The null hypothesis under examination was that all isolates identified as $F$. nucleatum by independent methods are genetically homogeneous (i.e., they belong to the same species).

\section{MATERIALS AND METHODS}

Microorganisms. Forty-four isolates of $F$. nucleatum (Table 1) were investigated in the present study. The type strains of the five subspecies (4-6) were included, together with 13 isolates previously assigned to one of these subspecies on the basis of homology of the cellular fatty acid profiles and whole-cell protein profiles with the profiles of one of the type strains. The subspecies determination study was performed prior to the present study by L. Holdeman-Moore, Virginia Polytechnic Institute and State University, Blacksburg. The purity of isolates was confirmed during manipulations by using Gram staining, cell morphology, anaerobic growth, and resistance to vancomycin and nalidixic acid. Isolate VPI 4487 (F. nucleatum subsp. vincentii) divided into smooth and rough colonies during anaerobic growth on blood agar; the two colony types were purified, were des- ignated $\mathrm{S}$ and $\mathrm{R}$, respectively, and were electrophoretically examined as separate isolates (Table 1). All 44 isolates were stored in glycerol broth at $-80^{\circ} \mathrm{C}$ until they were required.

Preparation and electrophoresis of bacterial cell lysates. The test organisms were grown anaerobically for 2 to 3 days at $37^{\circ} \mathrm{C}$ on blood agar plates, and confluent growth was harvested in ca. $1 \mathrm{ml}$ of $100 \mathrm{mM}$ Tris- $\mathrm{HCl}$ buffer $(\mathrm{pH} 8.0)$. The cells were then centrifuged, the supernatants were removed, and the resulting cell pellets were stored at $-80^{\circ} \mathrm{C}$.

Prior to electrophoresis, the pellets were thawed at room temperature and resuspended in an equivalent volume of lysis buffer consisting of $0.1 \% \beta$-mercaptoethanol and $100 \mu \mathrm{g}$ of NADP (Sigma Chemical Co.) per $\mathrm{ml}$ in $100 \mathrm{ml}$ of $\mathrm{H}_{2} \mathrm{O}$. The resuspended cells were kept on ice and ultrasonically disrupted. The lysed cell suspensions were then centrifuged at $5,000 \times g$ for $10 \mathrm{~min}$ at $4^{\circ} \mathrm{C}$, and the cell lysates (supernatants) were collected in capillary tubes as $5-\mu 1$ aliquots and stored at $-20^{\circ} \mathrm{C}$.

The supernatants were thawed, and approximately $0.5-\mu$ l aliquots were electrophoresed on a cellulose acetate (Cellogel; Chemetron, Milan, Italy) support medium at $200 \mathrm{~V}$ for 1 to $1.5 \mathrm{~h}$ at $4^{\circ} \mathrm{C}$.

A total of 21 enzyme loci exhibited sufficient staining intensity, resolution, and separation to allow reliable allozymic scoring. Loci for the following enzymes were examined: acid phosphatase (EC 3.1.3.2), adenylate kinase (EC 2.7.4.3), alkaline phosphatase (EC 3.1.3.1), diaphorase (EC 1.6.2.2), enolase (EC 4.2.1.11), glutamate dehydrogenase (EC 1.4.1.3), aspartate aminotransferase (synonym, glutamate oxaloacetate transaminase) (EC 2.6.1.1), glucose-phos- 
phate isomerase (EC 5.3.1.9), alanine aminotransferase (synonym, glutamate pyruvate transaminase) (EC 2.6.1.2), hexokinase (EC 2.7.1.1), lactate dehydrogenase (EC 1.1.1.27), malate dehydrogenase (EC 1.1.1.37), purine nucleoside phosphorylase (EC 2.4.2.1), nucleoside diphosphate kinase (EC 2.7.4.6), 2-oxoglutarate reductase (EC 1.2.4.2), leucine-glycine-glycine peptidase (EC 3.4.11.4), phosphoglycerate mutase (EC 2.7.5.3), phosphoglucomutase (EC 2.7.5.1), pyruvate kinase (EC 2.7.1.40), triose-phosphate isomerase (EC 5.3.1.1), and uridine diphosphatc kinase (EC 2.7.4.6). The enzymes were histochemically stained by using the methods described by Richardson et al. (19) and Selander et al. (23)

All 21 enzymes tested in the present study were polymorphic for the isolates tested. The electrophoretic band patterns were allozymically scored in order of increasing anodal migration (Table 2) and were interpreted by using fixed differences as the genetic distance measure (see reference 17 for a detailed discussion). Each isolate was compared individually to each of the other isolates to obtain a matrix of percentages of fixed genetic difference between the isolates tested. The results are presented visually as a phenogram in Fig. 1, which was constructed by using the unweighted pair group method of analysis (19).

\section{RESULTS}

Table 2 shows the allelic profiles of $44 F$. nucleatum isolates at 21 enzyme loci. Figure 1 is the phenogram derived from the allelic profiles and shows the fixed genetic differences between isolates. Three distinct genetic groups of isolates were identified, and the fixed differences between groups ranged from $82.5 \%$ of the loci (group I compared with group II) to $90 \%$ of the loci (groups I and II compared with group III). The withingroup variations were approximately equivalent in groups I and II, with the fixed differences ranging from 0 to $79.4 \%$. Group III was defined by a single isolate, SG2.

Genetic group I. The isolates which defined group I were 3322, Fev-1, ATCC $10953^{\mathrm{T}}$ ( $\mathrm{T}=$ type strain), ATCC $49256^{\mathrm{T}}$, $10446,10772, \mathrm{M} \mathrm{4322,}$ M 3832, NCTC $11326^{\mathrm{T}}$, D213B3, D218B17, M 7731, 10625, F6, D206A4, VPI 8818, F1, F3, 10554, M 2109, 3943, 3352, 3949, VPI 8754A, ATCC $25586^{\mathrm{T}}$, 10213, OMZ439, and SV2. Isolate SV2 differed from all of the other isolates in group I at $79.4 \%$ of the 21 enzyme loci examined and formed a unique genetic cluster. The remaining isolates in group I could be divided into six clusters that exhibited approximately equal levels of within-cluster genetic variation. Each of these six clusters exhibited fixed genetic differences with the other clusters which ranged from 54.9 to $79.7 \%$ of the 21 enzyme loci examined.

The first cluster contained isolates VPI 8754A, ATCC $25586^{\mathrm{T}}, 10213$, and OMZ439. The genetic variation within this cluster was much greater than the variation observed in the other five clusters, ranging from 31 to $69 \%$ of the loci. It is interesting that this was the genetic cluster which contained ATCC 25586, the type strain of $F$. nucleatum and $F$. nucleatum subsp. nucleatum. The second cluster contained isolates 3943, 3352, and 3949. The levels of genetic heterogeneity within this cluster ranged from 24 to $36 \%$ of the loci. The third cluster contained isolates 3322, Fev-1, ATCC $10953^{\mathrm{T}}$, ATCC $49256^{\mathrm{T}}$, 10446 , and 10772 , and the genetic variation within this cluster ranged from 28 to $48.8 \%$ of the loci. The fourth cluster contained isolates $M$ 4322, M 3832, NCTC 11326, D213B3, D218B17, and M 7731; the within-cluster variation for this cluster ranged from 24 to $42.5 \%$ of the loci examined. The fifth cluster contained isolates 10625, F6, D206A4, VPI 8818, F1, and F3; within this cluster, the genetic variation ranged from 0 to $49 \%$ of the loci. The sixth cluster contained isolates 10554 and M 2109, which differed from each other at $41 \%$ of the loci.

Genetic group II. The second group contained isolates KE393, KE255, G34, I34, I37, VPI 6086, AIP486-87, 10735, VPI 6616D, VPI 5040, VPI 9240, VPI 4487R, VPI 4487S, NCTC $12276^{\mathrm{T}}$, and 10976 . Within group II, there were five distinct genetic clusters of isolates which differed from each other at 53.4 to $78.7 \%$ of the loci examined; these values were comparable to the levels of genetic variation between clusters in group I. The first group II cluster contained isolates KE393, KE255, G34, I34, and I37, and the within-cluster variation ranged from 7 to $34.3 \%$ of the loci. The second cluster contained isolates VPI 6086, AIP486-87, 10735, and VPI 6616D, and the within-cluster genetic variation of this cluster ranged from 29 to $43.7 \%$ of the loci. The third group II cluster contained a single isolate, VPI 5040. The fourth cluster contained isolates VPI 9240, VPI 4487R, and VPI 4487S, which exhibited fixed differences ranging from 24 to $42 \%$ of the loci. Isolates NCTC $12276^{\mathrm{T}}$ and 10976 belonged to the fifth cluster of group II and differed from each other at $50 \%$ of the loci.

Genetic group III. A single isolate, SG2, defined the third genetic group. This organism differed from all of the other isolates tested at an average of $90 \%$ of the 21 enzyme loci studied.

\section{DISCUSSION}

For the $44 \mathrm{~F}$. nucleatum isolates examined in the present study, fixed differences were detected at 0 to $90 \%$ of the 21 previously established enzyme loci examined (17). Despite the fact that isolate SG2 was biologically classified as a member of the species $F$. nucleatum by independent investigators (Institute of Medical and Veterinary Science, Adelaide, South Australia, Australia), who used standard diagnostic techniques, it formed a unique genetic group. The remaining 43 isolates of $F$. nucleatum were divided into two major groups which differed from each other at an average of $82.5 \%$ of the 21 enzyme loci examined. This value is equivalent to or higher than the genetic distance measures that define some other prokaryotic and bacterial species.

Genetic group I. Isolate SV2 exhibited a high degree of genetic variation compared to the other isolates in group I. This isolate may represent the extent of genetic heterogeneity in this group, or it may be the only representative of an extensive genetic cluster that could be defined with additional clinical isolates.

Four isolates derived from cat oral cavities were members of group I, but there was an average fixed difference of $54.3 \%$ between isolate 3322 , which was obtained from a periodontally diseased site, and the other three isolates. The remaining catderived isolates formed a genetically distinct cat-specific cluster. These results imply that isolate 3352 , which clustered with two isolates obtained from healthy cat oral cavities, may have been isolated from an opportunistic infection, while isolate 3322 , which was genetically distinct, may represent a pathogenic, cat-specific genetic cluster. Alternatively, isolate 3322 may have been obtained from an infection due to human contamination, which would explain why it was genetically more closely related to a number of human oral isolates than to the three other cat oral isolates. M 3832 is an isolate that was obtained from a dog bite wound abscess. This isolate clustered with a number of human oral isolates, which implies that the infecting organism may have been transmitted from the dog's owner to the dog. Alternatively, $F$. nucleatum isolates derived from dogs may be more closely genetically related to isolates found in the oral cavities of human than to isolates found in the oral cavities of cats. Isolate NCTC 12276 has been designated the type strain of $F$. nucleatum subsp. animalis and therefore was used as a representative of all of the isolates derived from animals. However, the results of the present study indicate that this isolate differed from the other animal isolates at an average of $82.5 \%$ of the loci; therefore, its use as an animal type strain is inappropriate. NCTC $12276^{\mathrm{T}}$ could perhaps be used as a type strain for the animal extraoral isolates in group II, but an alternative animal oral type strain must be chosen for group I. 


\begin{tabular}{|c|c|c|c|c|c|c|c|c|c|c|c|c|c|c|c|c|c|c|c|c|c|c|}
\hline \multirow{2}{*}{ Isolate } & \multirow{2}{*}{ Subspecies } & \multicolumn{21}{|c|}{ Enzyme locia ${ }^{a}$} \\
\hline & & $\overline{\mathrm{ACP}}$ & $\mathrm{AK}$ & $\mathrm{AP}$ & DIA & ENOL & GDH & GOT & GPI & GPT & HK & LDH & $\mathrm{MDH}$ & NDPK & NP & OGR & Pep-B & PGAM & PGM & PK & TPI & UMPK \\
\hline ATCC $25586^{\mathrm{T}}$ & F. nucleatum subsp. nucleatum & $\mathrm{d}$ & $\mathrm{c}$ & $\mathrm{b}$ & & $\mathrm{b}$ & $\mathrm{b}$ & $\mathrm{d}$ & $\mathrm{b}$ & $\mathrm{e}$ & a & $\mathrm{b}$ & $\mathrm{C}$ & $\mathrm{c}$ & $\mathrm{g}$ & $\mathrm{g}$ & $\mathrm{b}$ & $\mathrm{f}$ & $\mathrm{a}$ & a & $\mathrm{h}$ & $\mathrm{b}$ \\
\hline Fev-1 & F. nucleatum subsp. nucleatum & b & $\mathrm{g}$ & $\mathrm{c}$ & d & $\mathrm{c}$ & $\mathrm{c}$ & $\mathrm{g}$ & $\mathrm{c}$ & $\mathrm{c}$ & $\mathrm{c}$ & $\mathrm{d}$ & $\mathrm{C}$ & d & b & $\mathrm{d}$ & $\mathrm{b}$ & d & $\mathrm{c}$ & $\mathrm{c}$ & $\mathrm{h}$ & $\mathrm{b}$ \\
\hline VPI 5040 & F. nucleatum subsp. nucleatum & a & a & & $\mathrm{c}$ & d & d & a & $\mathrm{b}$ & $\mathrm{c}$ & & b & & a & $\mathrm{c}$ & b & & $\mathrm{c}$ & b & & d & $\mathrm{a}$ \\
\hline VPI 9240 & F. nucleatum subsp. nucleatum & $\mathrm{e}$ & $\mathrm{b}$ & & & $\mathrm{c}$ & b & & $\mathrm{b}$ & a & $\mathrm{b}$ & $\mathrm{c}$ & B & $\mathrm{b}$ & $\mathrm{c}$ & a & d & b & $\mathrm{b}$ & & b & \\
\hline ATCC $10953^{\mathrm{T}}$ & F. nucleatum subsp. polymorphum & $\mathrm{b}$ & $\mathrm{g}$ & $\mathrm{c}$ & $\mathrm{c}$ & a & $\mathrm{c}$ & & $\mathrm{c}$ & $\mathrm{c}$ & $\mathrm{c}$ & & A & $\mathrm{e}$ & $\mathrm{b}$ & d & $\mathrm{b}$ & $\mathrm{f}$ & $\mathrm{b}$ & $\mathrm{c}$ & $\mathrm{h}$ & $\mathrm{b}$ \\
\hline D206A4 & F. nucleatum subsp. polymorphum & $\mathrm{b}$ & $\mathrm{g}$ & $\mathrm{b}$ & $\mathrm{c}$ & d & $\mathrm{c}$ & $\mathrm{f}$ & $\mathrm{f}$ & $\mathrm{c}$ & d & d & A & $\mathrm{e}$ & a & d & $\mathrm{b}$ & $\mathrm{e}$ & $\mathrm{b}$ & $\mathrm{c}$ & $\mathrm{h}$ & b \\
\hline F1 & F. nucleatum subsp. polymorphum & $\mathrm{b}$ & $\mathrm{e}$ & $\mathrm{b}$ & $\mathrm{c}$ & $\mathrm{b}$ & $\mathrm{c}$ & $\mathrm{h}$ & $\mathrm{e}$ & $\mathrm{c}$ & $\mathrm{d}$ & $\mathrm{c}$ & A & d & $\mathrm{b}$ & d & $\mathrm{c}$ & $\mathrm{f}$ & d & $\mathrm{c}$ & $\mathrm{h}$ & b \\
\hline F3 & F. nucleatum subsp. polymorphum & $b$ & $\mathrm{e}$ & $\mathrm{b}$ & $\mathrm{c}$ & b & $\mathrm{c}$ & $\mathrm{h}$ & $\mathrm{e}$ & $\mathrm{c}$ & d & $\mathrm{c}$ & A & d & $\mathrm{b}$ & d & $\mathrm{c}$ & $\mathrm{f}$ & d & & $\mathrm{h}$ & $\mathrm{b}$ \\
\hline VPI 8818 & F. nucleatum subsp. polymorphum & $\mathrm{b}$ & $\mathrm{f}$ & d & $\mathrm{e}$ & $\mathrm{d}$ & $\mathrm{c}$ & $\mathrm{e}$ & $\mathrm{c}$ & $\mathrm{c}$ & $\mathrm{d}$ & $\mathrm{c}$ & A & d & $\mathrm{b}$ & d & $\mathrm{c}$ & $\mathrm{f}$ & $\mathrm{c}$ & $\mathrm{c}$ & 1 & $\mathrm{~b}$ \\
\hline NCTC $11326^{\mathbf{T}}$ & F. nucleatum subsp. fusiforme & $\mathrm{b}$ & $\mathrm{g}$ & $\mathrm{c}$ & $\mathrm{e}$ & d & b & $\mathrm{f}$ & $\mathrm{b}$ & $\mathrm{c}$ & $\mathrm{c}$ & d & A & $\mathrm{d}$ & $\mathrm{b}$ & $\mathrm{d}$ & a & $\mathrm{e}$ & $\mathrm{b}$ & $\mathrm{d}$ & $\mathrm{h}$ & $\mathrm{b}$ \\
\hline ATCC $49256^{\mathbf{T}}$ & F. nucleatum subsp. vincentii & $\mathrm{b}$ & $\mathrm{g}$ & $\mathrm{b}$ & $\mathrm{b}$ & $\mathrm{b}$ & $\mathrm{c}$ & $\mathrm{g}$ & d & $\mathrm{d}$ & $\mathrm{c}$ & d & $\mathrm{C}$ & d & $\mathrm{b}$ & $\mathrm{d}$ & $\mathrm{b}$ & $\mathrm{e}$ & $\mathrm{c}$ & $\mathrm{c}$ & $\mathrm{g}$ & \\
\hline D213B3 & F. nucleatum subsp. vincentii & b & $\mathrm{f}$ & $\mathrm{b}$ & $\mathrm{c}$ & $\mathrm{d}$ & b & $\mathrm{f}$ & $\mathrm{b}$ & $\mathrm{d}$ & $\mathrm{c}$ & a & $\mathrm{C}$ & $\mathrm{d}$ & b & d & a & $\mathrm{e}$ & $\mathrm{b}$ & $\mathrm{c}$ & $\mathrm{g}$ & b \\
\hline D218B17 & F. nucleatum subsp. vincentii & $\mathrm{b}$ & $\mathrm{f}$ & $\mathrm{b}$ & $\mathrm{b}$ & d & b & d & $\mathrm{b}$ & $\mathrm{c}$ & $\mathrm{c}$ & $\mathrm{a}$ & A & d & $\mathrm{b}$ & $\mathrm{d}$ & $\mathrm{a}$ & $\mathrm{b}$ & $\mathrm{b}$ & $\mathrm{c}$ & $\mathrm{g}$ & b \\
\hline VPI 4487R & F. nucleatum subsp. vincentii & $\mathrm{f}$ & $\mathrm{b}$ & $\mathrm{b}$ & & d & b & $b$ & $b$ & a & d & $\mathrm{c}$ & B & $\mathrm{b}$ & $b$ & a & $\mathrm{a}$ & $b$ & a & & a & \\
\hline VPI $4487 \mathrm{~S}$ & F. nucleatum subsp. vincentii & $\mathrm{f}$ & $\mathrm{b}$ & $\mathrm{b}$ & & $\mathrm{c}$ & $\mathrm{c}$ & 1 & $\mathrm{~b}$ & & d & $\mathrm{c}$ & B & b & $\mathrm{b}$ & a & $\mathrm{a}$ & b & $\mathrm{b}$ & & $\mathrm{a}$ & \\
\hline VPI 6086 & F. nucleatum subsp. vincentii & a & $\mathrm{a}$ & & $\mathrm{c}$ & $\mathrm{c}$ & $\mathrm{e}$ & & $\mathrm{b}$ & $\mathrm{b}$ & $\mathrm{c}$ & d & $\mathrm{B}$ & a & & $\mathrm{b}$ & & $\mathrm{b}$ & a & $\mathrm{a}$ & $\mathrm{d}$ & a \\
\hline VPI $6616 \mathrm{D}$ & F. nucleatum subsp. vincentii & a & $\mathrm{b}$ & & $\mathrm{c}$ & d & a & $\mathrm{b}$ & $\mathrm{b}$ & $\mathrm{b}$ & $\mathrm{c}$ & $\mathrm{b}$ & B & $\mathrm{b}$ & $\mathrm{b}$ & $\mathrm{b}$ & & $\mathrm{c}$ & b & $\mathrm{a}$ & $\mathrm{c}$ & $\mathrm{a}$ \\
\hline VPI $8754 \mathrm{~A}$ & F. nucleatum subsp. vincentii & & $\mathrm{c}$ & $b$ & $\mathrm{~b}$ & $\mathrm{c}$ & $\mathrm{b}$ & & & $\mathrm{d}$ & & d & & b & & $\mathrm{e}$ & b & $\mathrm{e}$ & $\mathrm{c}$ & & $\mathrm{f}$ & $\mathrm{b}$ \\
\hline NCTC $12276^{\mathrm{T}}$ & F. nucleatum subsp. animalis & $b$ & a & $\mathrm{c}$ & & b & $\mathrm{f}$ & $\mathrm{h}$ & $\mathrm{c}$ & & $\mathrm{c}$ & $\mathrm{c}$ & $\mathrm{C}$ & a & & $\mathrm{b}$ & d & $\mathrm{a}$ & $\mathrm{b}$ & & $\mathrm{b}$ & \\
\hline M 7731 & $\mathrm{ND}^{b}$ & $\mathrm{~b}$ & $\mathrm{~g}$ & $\mathrm{~b}$ & $b$ & c & b & d & b & $c$ & $\mathrm{c}$ & $\mathrm{d}$ & A & $\mathrm{d}$ & $\mathrm{b}$ & $\mathrm{d}$ & $\mathrm{a}$ & d & $\mathrm{a}$ & $\mathrm{c}$ & $\mathrm{g}$ & $\mathrm{b}$ \\
\hline M 4322 & ND & $\mathrm{b}$ & $\mathrm{g}$ & $\mathrm{b}$ & $\mathrm{c}$ & $\mathrm{d}$ & $\mathrm{b}$ & $\mathrm{g}$ & $\mathrm{f}$ & $\mathrm{c}$ & d & $\mathrm{c}$ & & d & $\mathrm{b}$ & d & a & $\mathrm{e}$ & $\mathrm{c}$ & $\mathrm{c}$ & $\mathrm{g}$ & $\mathrm{b}$ \\
\hline M 3832 & ND & $\mathrm{b}$ & $\mathrm{g}$ & & $\mathrm{b}$ & d & b & $\mathrm{f}$ & $\mathrm{c}$ & $\mathrm{b}$ & d & $\mathrm{b}$ & $\mathrm{C}$ & $\mathrm{d}$ & $\mathrm{b}$ & d & $\mathrm{a}$ & $\mathrm{f}$ & $\mathrm{c}$ & $\mathrm{c}$ & $\mathrm{g}$ & $\mathrm{b}$ \\
\hline M 2109 & ND & a & $\mathrm{g}$ & $\mathrm{b}$ & $\mathrm{e}$ & b & d & $\mathrm{g}$ & $\mathrm{c}$ & d & d & & $\mathrm{C}$ & $\mathrm{f}$ & $\mathrm{c}$ & d & b & $\mathrm{e}$ & $\mathrm{c}$ & $\mathrm{c}$ & 1 & \\
\hline SG2 & ND & & l & & $\mathrm{c}$ & $\mathrm{e}$ & $\mathrm{f}$ & $\mathrm{k}$ & $\mathrm{g}$ & & $\mathrm{c}$ & & & & $\mathrm{f}$ & & $\mathrm{e}$ & b & $\mathrm{f}$ & & $\mathrm{k}$ & $\mathrm{a}$ \\
\hline SV2 & ND & $\mathrm{a}$ & $\mathrm{h}$ & & $\mathrm{c}$ & d & $\mathrm{g}$ & $\hat{j}$ & $\mathrm{~h}$ & $\mathrm{e}$ & d & $\mathrm{a}$ & $\mathrm{C}$ & & $\mathrm{e}$ & & b & f & $\mathrm{f}$ & & $\mathrm{j}$ & $\mathrm{b}$ \\
\hline G34 & ND & & $\mathrm{b}$ & $\mathrm{c}$ & & d & b & & $\mathrm{c}$ & $\mathrm{b}$ & a & $\mathrm{a}$ & B & $\mathrm{b}$ & $\mathrm{d}$ & $\mathrm{b}$ & $\mathrm{a}$ & $\mathrm{c}$ & b & $\mathrm{a}$ & d & $\mathrm{a}$ \\
\hline I34 & ND & & b & $\mathrm{c}$ & & d & b & c & $\mathrm{a}$ & $b$ & $\mathrm{a}$ & a & & b & d & $\mathrm{b}$ & a & $\mathrm{f}$ & $\mathrm{b}$ & $\mathrm{a}$ & d & a \\
\hline I37 & ND & & $\mathrm{b}$ & $c$ & & $\mathrm{c}$ & $\mathrm{b}$ & $\mathrm{c}$ & $\mathrm{a}$ & $\mathrm{b}$ & $\mathrm{a}$ & & & $b$ & d & $\mathrm{b}$ & & $\mathrm{f}$ & $\mathrm{b}$ & & d & $\mathrm{a}$ \\
\hline 10976 & ND & $\mathrm{f}$ & $\mathrm{c}$ & $\mathrm{b}$ & & $\mathrm{b}$ & $\mathrm{b}$ & $\mathrm{h}$ & $\mathrm{c}$ & $\mathrm{a}$ & d & $\mathrm{c}$ & $\mathrm{C}$ & $\mathrm{c}$ & d & $\mathbf{a}$ & d & a & b & & $\mathrm{a}$ & \\
\hline 10625 & ND & $\mathrm{c}$ & $\mathrm{d}$ & $\mathrm{b}$ & $\mathrm{c}$ & d & d & $\mathrm{g}$ & d & $\mathrm{c}$ & b & & A & $\mathrm{e}$ & b & d & c & $\mathrm{e}$ & $b$ & $\mathrm{c}$ & 1 & $\mathrm{~b}$ \\
\hline AIP486-87 & ND & $\mathrm{a}$ & $\mathrm{b}$ & & $\mathrm{c}$ & d & $b$ & b & b & $\mathrm{b}$ & $\mathrm{a}$ & d & B & $\mathrm{b}$ & $\mathrm{d}$ & $\mathrm{b}$ & & $\mathrm{b}$ & a & $\mathrm{a}$ & $\mathrm{e}$ & $\mathrm{a}$ \\
\hline 10772 & ND & b & $\mathrm{g}$ & $b$ & d & b & $\mathrm{d}$ & $\mathrm{g}$ & d & $\mathrm{c}$ & $\mathrm{d}$ & b & & $\mathrm{f}$ & $b$ & $\mathrm{c}$ & $b$ & d & $\mathrm{c}$ & $\mathrm{c}$ & d & b \\
\hline 10554 & ND & $\mathrm{c}$ & $\mathrm{e}$ & & c & $\mathrm{b}$ & $\mathrm{e}$ & & c & d & d & a & $\mathrm{C}$ & d & b & d & b & $\mathrm{e}$ & $\mathrm{c}$ & $\mathrm{c}$ & d & $\mathrm{a}$ \\
\hline 10735 & ND & a & b & & $\mathrm{c}$ & d & $\mathrm{e}$ & & d & $b$ & $\mathrm{a}$ & $\mathrm{e}$ & B & & $\mathrm{e}$ & $\mathrm{b}$ & a & d & a & $a$ & $\mathrm{e}$ & a \\
\hline 10213 & ND & d & $\mathrm{c}$ & & $\mathrm{e}$ & $\mathrm{b}$ & b & & $\mathrm{c}$ & $\mathrm{e}$ & a & & C & $\mathrm{c}$ & & $\mathrm{f}$ & a & $\mathrm{e}$ & b & $\mathrm{a}$ & $\mathrm{h}$ & $\mathrm{b}$ \\
\hline 10446 & ND & b & $\mathrm{g}$ & $b$ & d & $\mathrm{c}$ & $\mathrm{c}$ & & $\mathrm{e}$ & $\mathrm{c}$ & d & b & B & & $b$ & d & b & $\mathrm{c}$ & $\mathrm{c}$ & $\mathrm{c}$ & $\mathrm{d}$ & $\mathrm{b}$ \\
\hline 3322 & ND & $b$ & $\mathrm{e}$ & $b$ & a & $\mathrm{e}$ & $\mathrm{c}$ & $\mathrm{g}$ & d & $b$ & $\mathrm{e}$ & a & $\mathrm{C}$ & d & b & $\mathrm{d}$ & $\mathrm{b}$ & d & $\mathrm{c}$ & $\mathrm{c}$ & $\mathrm{h}$ & $b$ \\
\hline 3352 & ND & $\mathrm{c}$ & $\mathrm{f}$ & & $\mathrm{c}$ & d & $\mathrm{f}$ & & d & c & $\mathrm{e}$ & $\mathrm{a}$ & $\mathrm{C}$ & d & $\mathrm{b}$ & d & $\mathrm{c}$ & $\mathrm{c}$ & d & & $\mathrm{h}$ & $\mathrm{a}$ \\
\hline 3943 & ND & $\mathrm{c}$ & $\mathrm{e}$ & $\mathrm{a}$ & & $\mathrm{e}$ & $\mathrm{f}$ & $\mathrm{g}$ & d & $\mathrm{c}$ & $\mathrm{e}$ & $\mathrm{a}$ & A & d & $\mathrm{b}$ & d & $\mathrm{c}$ & $\mathrm{c}$ & $\mathrm{e}$ & & $\mathrm{h}$ & a \\
\hline 3949 & ND & $\mathrm{c}$ & $\mathrm{f}$ & & & c & $\mathrm{e}$ & & d & $\mathrm{c}$ & b & & A & d & b & d & $c$ & $\mathrm{f}$ & & $\mathrm{c}$ & $\mathrm{h}$ & \\
\hline KE255 & ND & $b$ & b & $\mathrm{c}$ & & $\mathrm{c}$ & b & $b$ & $\mathrm{c}$ & $\mathrm{b}$ & $\mathrm{c}$ & $b$ & & $\mathrm{~b}$ & d & $\mathrm{b}$ & $\mathrm{a}$ & $\mathrm{c}$ & $b$ & & $\mathrm{~h}$ & \\
\hline KE393 & ND & $\mathrm{b}$ & $\mathrm{b}$ & $\mathrm{c}$ & & c & $\mathrm{b}$ & $\mathrm{b}$ & $\mathrm{c}$ & $\mathrm{c}$ & a & $\mathrm{b}$ & & $\mathrm{b}$ & d & $\mathrm{b}$ & a & $\mathrm{c}$ & b & & $\mathrm{h}$ & a \\
\hline OMZ439 & ND & d & $\mathrm{c}$ & $b$ & $\mathrm{e}$ & d & $\mathrm{c}$ & i & $b$ & d & $b$ & $\mathrm{c}$ & A & & $\mathrm{h}$ & & $\mathrm{c}$ & $\mathrm{c}$ & $\mathrm{a}$ & $\mathrm{c}$ & $\mathrm{g}$ & $b$ \\
\hline F6 & ND & b & $\mathrm{g}$ & b & $\mathrm{c}$ & d & $\mathrm{c}$ & $\mathrm{f}$ & $\mathrm{b}$ & $\mathrm{c}$ & d & $\mathrm{c}$ & A & e & b & $\mathrm{d}$ & $\mathrm{c}$ & $\mathrm{g}$ & $\mathrm{b}$ & $\mathrm{b}$ & $\mathrm{h}$ & b \\
\hline
\end{tabular}

" Abbreviations: ACP, acid phosphatase; AK, adenylate kinase; AP, alkaline phosphatase; DIA, diaphorase; ENOL, enolase; GDH, glutamate dehydrogenase; GOT, aspartate aminotransferase (synonym, glutamate oxaloacetate transaminase); GPI, glucose-phosphate isomerase; GPT, alanine aminotransferase (synonym, glutamate pyruvate transaminase); HK, hexokinase; LDH, lactate dehydrogenase; MDH, malate dehydrogenase; NDPK, nucleoside diphosphate kinase; NP, purine nucleoside phosphorylase; OGR, 2-oxoglutarate reductase; Pep-B, peptidase leucine-glycine-glycine; PGAM, phosphoglyccrate mutase; PGM, phosphoglucomutase increasing anodal migration and are designated as such in uppercase letters.

${ }^{b} \mathrm{ND}$, not determined. 


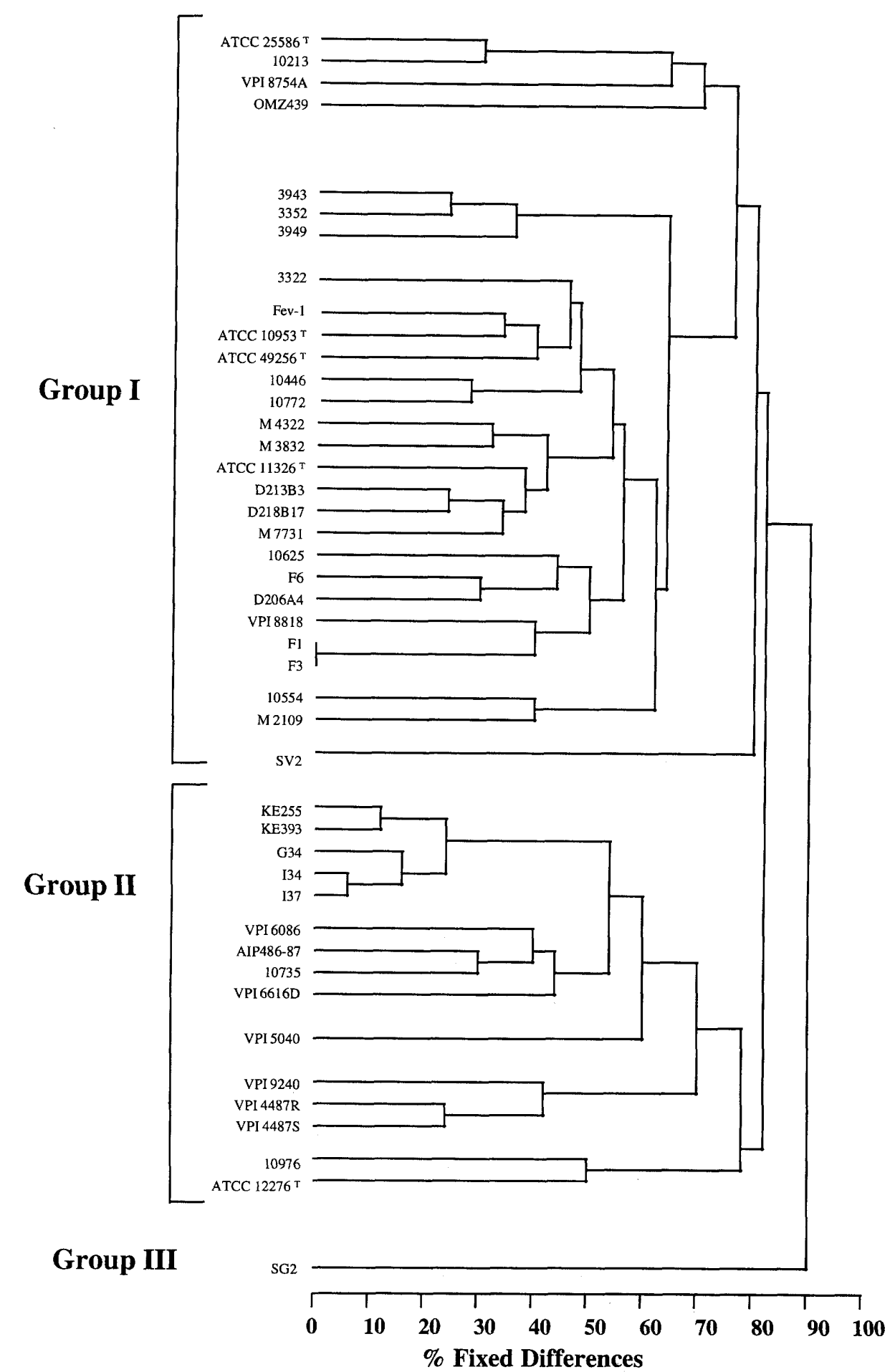

FIG. 1. Phenogram depicting the genetic relationships among 44 isolates of $F$. nucleatum based on an allozyme electrophoresis analysis in which 21 enzyme loci were used.

According to our results, isolates Fev-1, ATCC $10953^{\mathrm{T}}$, ATCC $49256^{\mathrm{T}}, 10446$, and 10772 all belong to a single genetic cluster. However, according to previous classifications (4-6), the first three of these isolates belong to $F$. nucleatum subsp. nucleatum, $F$. nucleatum subsp. polymorphum, and $F$. nucleatum subsp. vincentii, respectively, and strains ATCC 10953 and ATCC 49256 are the type strains of their respective subspecies.
The other isolates previously identified as members of these subspecies (Table 1) that are not located in this cluster appear to have been incorrectly identified; i.e., the type strains of these subspecies were genetically more closely related to each other than to the isolates that have been classified as members of the subspecies. The published relationships among $F$. nucleatum subsp. nucleatum, $F$. nucleatum subsp. polymorphum, and $F$. 
nucleatum subsp. vincentii are confusing. For example, Gharbia and Shah $(5,6)$ were not able to detect $F$. nucleatum subsp. vincentii, as identified by Dzink (4), and claimed that this taxon was identical to their $F$. nucleatum subsp. fusiforme. Our results indicate that $F$. nucleatum subsp. polymorphum and $F$. nucleatum subsp. vincentii are closely related genetically since the type strains of these subspecies were members of a single cluster.

A number of genetic clusters in group I consisted of isolates obtained from a range of sites of infection, suggesting that the isolates are opportunistic colonizers. However, genetic clusters which are diagnostically relevant and which consisted of a number of related isolates were identified. For example, isolates NCTC $11326^{\mathrm{T}}$, D213B3, and D218B17 were all obtained from healthy gingival sulci, indicating that their cluster may be a nonpathogenic cluster.

Isolates F1 and F3 have previously been identified as genetically homogeneous clones on the basis of their identical ribosomal DNA restriction patterns (3) and homologous restriction enzyme analysis results obtained by using probes for an outer membrane protein gene and a random segment of DNA (2). Our results support this genetic homology; indeed, these isolates were the only two isolates identical at all of the enzyme loci. This finding illustrates the accuracy and utility of allozyme electrophoresis in epidemiological and taxonomic investigations. It is interesting that although this cluster contained isolates belonging to $F$. nucleatum subsp. polymorphum, the type strain of this subspecies, ATCC 10953, was located in a different genetic cluster.

Genetic group II. Group II contained five clusters of isolates and a single type strain, NCTC 12276 ( $F$. nucleatum subsp. animalis; derived from the colon of a Macaque monkey). Isolates G34, I34, and I37 were obtained from three preterm labor patients. These isolates belonged to a single genetic cluster and exhibited minimal heterogeneity, indicating that they are closely related and possibly derived from a common infecting source. Isolate KE255, from a brain abscess, and isolate KE393, from a vaginal abscess, were both obtained from the same hospital and were in the same genetic cluster as isolates G34, I34, and I37. The four vaginal isolates could be distinguished from isolate KE255 on the basis of hexokinase enzyme mobility. The sex and age of the patient from whom isolate KE255 was obtained are unknown, but if this isolate was from a woman, not only would this genetic subdivision be a vaginal isolate-specific cluster, but it would be a female-specific $F$. nucleatum cluster.

One genetic cluster in group II consisted exclusively of isolates of gastrointestinal origin. The only gastrointestinal isolate not located in this cluster, VPI 5040 from a rectal abscess, was in a unique cluster whose average fixed difference with the previous cluster was $59 \%$. Perhaps the isolates obtained from gastrointestinal tract infections form a genetically related cluster but a cluster with higher-than-expected heterogeneity.

Isolates VPI 4487R and VPI 4487S are colony variants of a single clone which, interestingly, exhibited fixed genetic differences at $24 \%$ of the 21 loci examined, indicating that these organisms were not genetically identical.

Within group II, it appears that there are two types of clusters, namely, those that probably originated in the gastrointestinal tract and those that are female specific and originated in the vaginal tract. This observation implies that there are groups of isolates within the gastrointestinal tract that are genetically distinct from strains isolated from the vaginal tract, and these extraoral isolates form a distinct genetic group when they are compared to isolates of oral origin. Confirmation of the taxonomic relevance of the clusters identified in group II would require further information about the patients from whom the isolates were obtained and simultaneous testing of $F$. nucleatum isolates in individual patients from the site of infection, the oral cavity, the gastrointestinal tract, and, in the case of female patients, the genital tract.

Genetic group III. Genetic group III contained a single isolate, SG2, which exhibited fixed differences with the 43 other isolates tested at $90 \%$ of the enzyme loci examined. A possible explanation for this, given the inaccuracy of previously used $F$. nucleatum typing methods, is that this isolate was incorrectly assigned to this species. Alternatively, this isolate may represent the extremity of the genetic heterogeneity of the species.

Comparison with other biological methods of identification. The results of allozyme electrophoresis do not reflect the results obtained previously by methods such as fatty acid analysis, biochemical profile analysis, and analysis of the molar proportions of guanine and cytosine in the DNAs of $F$. nucleatum isolates (Fig. 2). For this reason, isolates SG2, SV2, ATCC 25586 (the type strain of $F$. nucleatum and $F$. nucleatum subsp. nucleatum), and NCTC 11326 (the type strain of $F$. nucleatum subsp. vincentii), which represent the extent of diversity within the $44 \mathrm{~F}$. nucleatum isolates used in the present study, were sent to an independent diagnostic laboratory for reidentification. On the basis of $\mathrm{G}+\mathrm{C}$ content and lipase activity, these strains were identified as members of a single species in the genus Fusobacterium. However, the results of a series of carbohydrate utilization tests identified isolate SG2 as the only "accurately identified" $F$. nucleatum isolate and isolate SV2 as a member of the closely related species Fusobacterium necrophorum. Clearly, this cannot be the case, as outlined in the present study (Fig. 1), where isolate SG2 is in group III, which suggests that alternative and reliable methods are required to genetically characterize the genus Fusobacterium and its species and subspecies. Our current and previous results (17) demonstrate that the use of allozyme electrophoresis for 21 enzyme loci provides a reliable method for genetic identification, characterization, and taxonomic classification of isolates of $F$. nucleatum.

Taxonomic implications of the present study. It is important to note that the separation of $F$. nucleatum isolates into distinct genetic groups in this study was not influenced by whether fixed differences or Nei's $D$ values were used as measures of genetic distance. The observed levels of genetic variation were equivalent to or higher than the levels detected in previous studies in which prokaryotic and bacterial species were defined (20-22). This study was not designed to provide a nomenclature or a taxonomic revision of the genus Fusobacterium. Such studies would require the use of additional type strains representing other fusobacterial species and closely related genera and a comparison of our results with results obtained by using other typing techniques with the same set of isolates. Nevertheless, the present study provides a sound genetic framework which can be used as the basis for an extensive study in which a range of taxonomically relevant techniques are used.

Our results highlight the problems associated with the use of inaccurately identified and characterized type strains, not only for taxonomic studies, but also for the subsequent identification, classification, and characterization of clinical isolates. An extensive epidemiological study must now be undertaken to unequivocally redefine the taxonomic divisions in the genus Fusobacterium. Type strains of other fusobacterial species and closely related genera must be included in such a study. Appropriate type strains can then be assigned to represent the taxonomic divisions. It is evident that the currently assigned type strains do not represent any of the distinct genetic clusters 


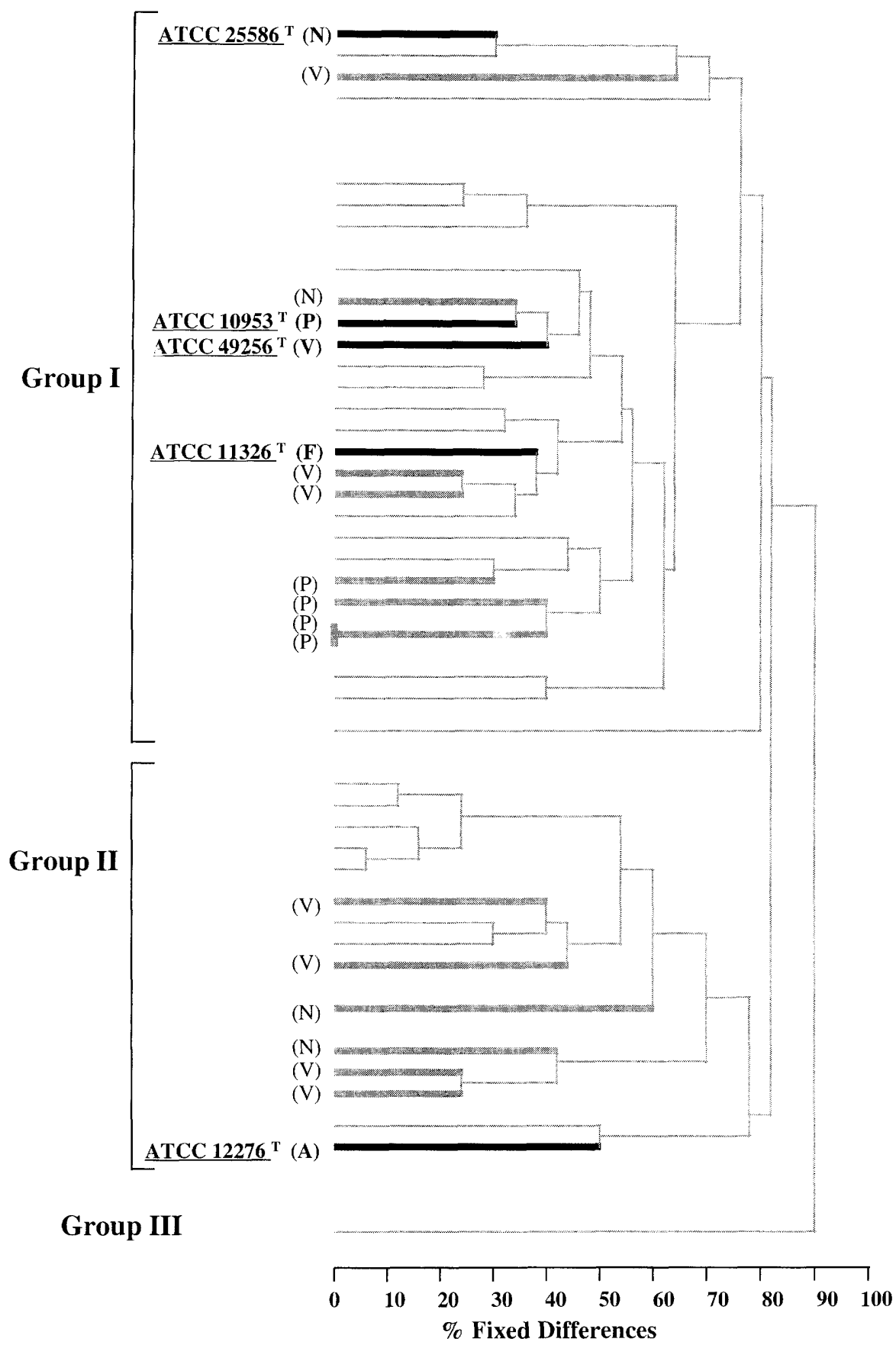

FIG. 2. Phenogram highlighting the genetic relationships among 13 isolates of $F$. nucleatum previously placed in subspecies (thick grey lines) and their relationships to the type strains of five identified subspecies (thick black lines), based on an allozyme electrophoresis analysis in which 21 enzyme loci were used. Abbreviations: (N), F. nucleatum subsp. nucleatum; (P), F. nucleatum subsp. polymorphum; (V), F. nucleatum subsp. vincentii; (F), F. nucleatum subsp. fusiforme; (A), F. nucleatum subsp. animalis.

of isolates identified in this study and that the currently identified species $F$. nucleatum consists of at least three distinct species (i.e., genetic groups I, II, and III).

\section{ACKNOWLEDGMENTS}

We thank Neil Chilton for helpful advice concerning the processing of data.

The financial support of the National Health and Medical Research Council of Australia, the Australian Dental Research Fund, Inc., and the Australian Research Council is gratefully acknowledged. R.H.A. gratefully acknowledges the financial support of the Faculty of Medicine, The University of Adelaide.

\section{REFERENCES}

1. Bennett, K. W., and A. Eley. 1993. Fusobacteria: new taxonomy and related diseases. J. Med. Microbiol. 39:246-254.

2. Bolstad, A., N. Skaug, and H. B. Jensen. 1991. Use of synthetic oligonucleotide DNA probes for the identification of different strains of Fusobacterium nucleatum. J. Periodontal Res. 26:519-526.

3. Bolstad, A. (University of Bergen). 1993. Personal communication.

4. Dzink, J. L., M. T. Sheenan, and S. S. Socransky. 1990. Proposal of three subspecies of Fusobacterium nucleatum Knorr 1922: Fusobacterium nuclea- 
tum subsp. nucleatum subsp. nov., comb. nov.; Fusobacterium nucleatum subsp. polymorphum subsp. nov., nom. rev., comb. nov.; and Fusobacterium nucleatum subsp. vincentii subsp. nov., nom. rev., comb. nov. Int. J. Syst. Bacteriol. 40:74-78.

5. Gharbia, S. E., and H. N. Shah. 1992. Fusobacterium nucleatum subsp. fusiforme subsp. nov, and Fusobacterium nucleatum subsp. animalis subsp. nov. as additional subspecies within Fusobacterium nucleatum. Int. J. Syst. Bacteriol. 42:296-298.

6. Gharbia, S. E., and H. N. Shah. 1990. Heterogeneity within Fusobacterium nucleatum, proposal of four subspecies. Lett. Appl. Microbiol. 10:105-108.

7. Gharbia, S. E., and H. N. Shah. 1990. Identification of Fusobacterium species by the electrophoretic migration of glutamate dehydrogenase and 2-oxoglutarate reductase in relation to their DNA base composition and peptidoglycan dibasic amino acids. J. Med. Microbiol. 33:183-188.

8. Gharbia, S. E., and H. N. Shah. 1991. Isolation, purification and characterisation of 2-oxoglutarate reductase from Fusobacterium nucleatum. FEMS Microbiol. Lett. 80:283-288.

9. Gharbia, S. E., H. N. Shah, P. A. Lawson, and M. Haapsalo. 1990. The distribution and frequency of Fusobacterium nucleatum subspecies in the human oral cavity. Oral Microbiol. Immunol. 5:324-327.

10. Hofstad, T. 1992. The genus Fusobacterium, p. 4114-4126. In A. Balows, H. G. Trüper, M. Dworkin, W. Harder, and K.-H. Schleifer (ed.), The prokaryotes. A handbook on the biology of bacteria: ecophysiology, isolation, identification, applications, 2nd ed., vol. IV. Springer-Verlag, New York, N.Y.

11. Holst, E., A. R. Goffeng, and B. Andersch. 1994. Bacterial vaginosis and vaginal microorganisms in idiopathic premature labor and association with pregnancy outcome. J. Clin. Microbiol. 32:176-186.

12. Lawson, P. A., S. E. Gharbia, H. N. Shah, and D. R. Clark. 1989. Recognition of Fusobacterium nucleatum subgroups Fn-1, Fn-2 and Fn-3 by ribosomal RNA gene restriction patterns. FEMS Microbiol. Lett. 65:41-46.

13. Lawson, P. A., S. E. Gharbia, H. N. Shah, D. R. Clark, and M. D. Collins. 1991. Intrageneric relationships of members of the genus Fusobacterium as determined by reverse transcriptase sequencing of small-subunit rRNA. Int. J. Syst. Bacteriol. 41:347-354.

14. Magee, J. T., J. M. Hindmarch, K. W. Bennett, B. I. Duerden, and R. E.
Aries. 1989. A pyrolysis mass spectrometry study of fusobacteria. J. Med. Microbiol. 28:227-236.

15. Moore, W. E. C., L. V. Holdeman, and R. W. Kelley. 1984. Genus II. Fusobacterium Knorr 1922, p. 631-637. In N. R. Krieg and J. G. Holt (ed.), Bergey's manual of systematic bacteriology, vol. 1. Williams and Wilkins, Baltimore, $\mathrm{Md}$.

16. Moore, W. E. C., and L. V. H. Moore. 1994. The bacteria of periodontal diseases. Periodontol. 2000 5:66-77.

17. Morris, M. L., R. H. Andrews, and A. H. Rogers. 1996. The use of allozyme electrophoresis to assess genetic heterogeneity among previously subspeciated isolates of Fusobacterium nucleatum. Oral Microbiol. Immunol. 11:1521.

18. Nørrung, B., and P. Gerner-Smidt. 1993. Comparison of multilocus enzyme electrophoresis (MEE), ribotyping, restriction enzyme analysis (REA) and phage typing for typing of Listeria monocytogenes. Epidemiol. Infect. 111: 71-79.

19. Richardson, B. J., P. R. Baverstock, and M. Adams. 1986. Allozyme electrophoresis: a handbook for animal systematics and population studies. Academic Press, Sydney, Australia.

20. Selander, R. K. 1980 . Genetic diversity and structure in Escherichia coli populations. Science 210:545-547.

21. Selander, R. K., T. K. Korhonen, V. Väisänen-Rhen, P. H. Williams, P. E. Pattison, and D. A. Caugant. 1986. Genetic relationship and clonal structure of strains of Escherichia coli causing neonatal septicemia and meningitis. Infect. Immun. 52:213-222.

22. Selander, R. K., R. M. McKinney, T. S. Whittam, W. F. Bibb, D. J. Brenner, F. S. Nolte, and P. E. Pattison. 1985. Genetic structure of populations of Legionella pneumophila. J. Bacteriol. 163:1021-1037.

23. Selander, R. K., D. A. Caugant, H. Ochman, J. M. Musser, M. N. Gilmour, and T.S. Whittam. 1986. Methods of multilocus enzyme electrophoresis for bacterial population genetics and systematics. Appl. Environ. Microbiol. 51:873-884.

24. Xie, H., R. J. Gibbons, and D. I. Hay. 1991. Adhesive properties of strains of Fusobacterium nucleatum of the subspecies nucleatum, vincentii and polymorphum. Oral Microbiol. Immunol. 6:257-263. 